\title{
Religion, public space and education
}

\section{Peta Goldburg ${ }^{1}$}

Published online: 15 October 2018

(c) Australian Catholic University 2018

In this special issue of the Journal of Religious Education, 'Religion, public space and education', we are pleased to welcome Professor Martin Ubani and Eveliina Ojala as guest editors.

The articles of the special issue are extended works that were selected from keynote and other presentations from the 14th Nordic Conference on Religious Education (NCRE) which took place from 12 to 15 June 2017 at the University of Eastern Finland. The theme of the conference was: "Religions, cultures and dialogue in learning environments and beyond". NCRE2017 was hosted both by the School of Theology and the School of Applied Educational Science and Teacher Education. Established in 1977, the NCRE has become one of the integral international conferences in religious education. At NCRE2017, there were 120 participants not just from the Nordic and Baltic countries but also from other parts of the world, including USA, UK, Belgium, Turkey and Ghana. The conference chair was Professor Martin Ubani.

The articles selected for this special issue include authors from five countries: Finland, Norway, Israel, Sweden and the UK. This reflects the international character of the discussions which took place at the conference. The six articles show how the question of religion, public space and education takes form in the levels of policy, structures and practices.

Peta Goldburg

peta.goldburg@acu.edu.au

1 Brisbane, Australia 